\title{
LETTER
}

\section{Transforming the Loess Plateau of China}

\author{
Yuheng LI ${ }^{1}$, Guoming DU ${ }^{2}$, Yansui LIU $(\bowtie)^{1,3}$ \\ 1 Institute of Geographic Sciences and Natural Resources Research, Chinese Academy of Sciences, Beijing 100101, China \\ 2 College of Resources and Environment, Northeast Agricultural University, Harbin 150030, China \\ 3 College of Resources Science and Technology, Beijing Normal University, Beijing 100875, China
}

\begin{abstract}
This paper aims to show the importance of land consolidation in transforming the Loess Plateau of China. The paper comprehensively analyzes how over recent decades the Grain for Green Project and Gully Land Consolidation Project jointly transformed the ecology and landscape of the Loess Plateau and the livelihood of its residents. The findings show that these two projects have achieved a balance between green protection, new land creation, and improved food security and livelihood of local people in the hilly areas of China. The paper points out that the successful transformation of the Plateau lies in a holistic approach incorporating various components of the human and natural systems. Finally, the paper highlights the necessity of retaining these two land consolidation projects as part of an ongoing policy in the mountain and hilly areas of China, changing agricultural management to suit the new relationship between humans and the land.
\end{abstract}

Keywords China, critical zone, land consolidation, Loess Plateau, sustainability

\section{Introduction}

After the Earth's Critical Zone was suggested by the US National Research Council in $2001^{[1]}$, experts called for zone understanding and its application to sustaining human needs, which will expand greatly in the next few decades ${ }^{[2,3]}$. The Loess Plateau of China covers an area of $640000 \mathrm{~km}^{2}$ in the upper and middle reaches of the Yellow River, and has been known to the world because it has the most highly erodible soil on earth, susceptible to the forces of wind and water ${ }^{[4]}$. Its shift from a highly vegetated area to an ecologically fragile place over the

Received May 23, 2016; accepted July 20, 2016

Correspondence: liuys@bnu.edu.cn centuries, clearly demonstrates the unbalanced relationship between humans and the land in this area. Recently, the Loess Plateau has regained world attention due to its increased vegetation coverage and improved ecological quality. Most notably, the land consolidation measures have dramatically transformed the ecology and landscape of the Plateau and the livelihoods of its residents, turning it from yellow to green. The aim of this paper is to describe the role of land consolidation in transforming the Loess Plateau of China.

\section{History of the Loess Plateau}

The Loess Plateau is located in the upper and middle reaches of the Yellow River in North-west China. As the largest area of loess in the world, it covers an area of more than $600000 \mathrm{~km}^{2}$, representing $6.6 \%$ of the territory in China. The Plateau, because of its thick but loose and fine soil, is known as one of the key agricultural areas in the country. However, the semiarid climate, with only $464.1 \mathrm{~mm}$ of average annual precipitation contributes to the fragility of the loess ecosystem.

In the quaternary and particularly the Holocene periods, the Loess Plateau was dominated by grassland and forest steppe ${ }^{[5]}$. However, centuries of deforestation and overgrazing, exacerbated by population increase, resulted in a degenerated ecosystems, desertification and poor local economies ${ }^{[6]}$. Poverty in turn aggravated desperate activities of local residents in claiming farmland, firewood and timber from the Plateau without regard for the environmental consequences. As a result, this vicious circle led to considerable degradation of the ecological quality of the Plateau, making it a region of over 270000 gullies (each with a length over $500 \mathrm{~m}$ ), which has seriously hindered socioeconomic development on the Plateau.

Ever since the 1950s, many attempts at improvements, such as terrace construction and small watershed management, have made by the government. However, these 
measures failed to alter the declining ecological conditions of the Plateau because of the relationship between humans and the land. People's livelihoods still largely relied on subsistence farming by constantly reclaiming sloping land. Thus, the ever increasing human activity caused daunting challenges for ecosystem rehabilitation. The average erosion on the Plateau was around $5000-10000 \mathrm{t} \cdot \mathrm{km}^{-2[7]}$, with the highest up to 20000-30000 $\mathrm{t} \cdot \mathrm{km}^{-2}$, which has been the major source of sediments in the Yellow River.

\section{Operations on the Plateau}

\subsection{Grain for Green Project}

The history of vegetation restoration in the Loess Plateau dates back to the $1970 \mathrm{~s}^{[8]}$. In 1999 , the Chinese government started implementing the Grain for Green (GFG) Project to convert farmland to forests, shrub land and grassland, aiming to counteract soil erosion and other environmental problems in ecologically fragile areas such as the Loess Plateau. Being the most ambitious, national ecological restoration program in China, the GFG Project committed an investment of over 40 billion USD by $2050^{[9]}$. About 28.8 billion USD has been invested in the conversion of cultivated land on steep slopes $\left(\geqslant 25^{\circ}\right)$ to perennial vegetation over the last decade ${ }^{[10]}$.

Farmers affected are compensated with food, living allowance and provision of saplings and also granted the ownership of the forests and pastures planted on their land. According to the regulations of the GFG Project, farmers affected will receive $1500 \mathrm{~kg}$ grain per hectare together with monetary compensation of $300 \mathrm{CNY}$ per hectare every year. Additionally, a disposal compensation of $750 \mathrm{CNY}$ per hectare for saplings and forestation will also be provided to the farmers. With these compensations, most farmers are released from farming and turn to nonagricultural work in towns and cities. Also, they are encouraged to relocate from sparsely distributed villages to newly built rural communities. As a result of these measures, ecological conservation of the Plateau has become possible. From 1999 to 2011, the GFG Project has been applied to nearly 29 million $\mathrm{hm}^{2}$, of which 9.3 million $\mathrm{hm}^{2}$ is forests planted on former farmland and 19.7 million $\mathrm{hm}^{2}$ is afforestation of barren hills and wasteland $^{[11]}$. Yan'an, Shaanxi Province, which is located in the core area of the Loess Plateau, has had an increase in the forest and grass coverage from $46 \%$ to $67.7 \%$ (Fig. 1).

\subsection{Gully Land Consolidation Project}

The considerable success of the GFG Project has not been without challenges. First, there have been large reductions in arable land. In Shaanxi Province for example, arable land decreased by 1.14 million $\mathrm{hm}^{2}$ from 1996 to 2009, an area of $28.6 \%$ of the total arable land of Shaanxi Province in $2009^{[12]}$. Also, when the compensation period comes to the end, local farmers are in urgent need of new land for grain production, otherwise they might reclaim land on the re-vegetated slopes. Chen et al. also expressed concerns that food deficit might emerge when China decided to expand the GFG project after the initial 15-year period ended in $2013^{[13]}$. In addition, with the influx of workers, (a)

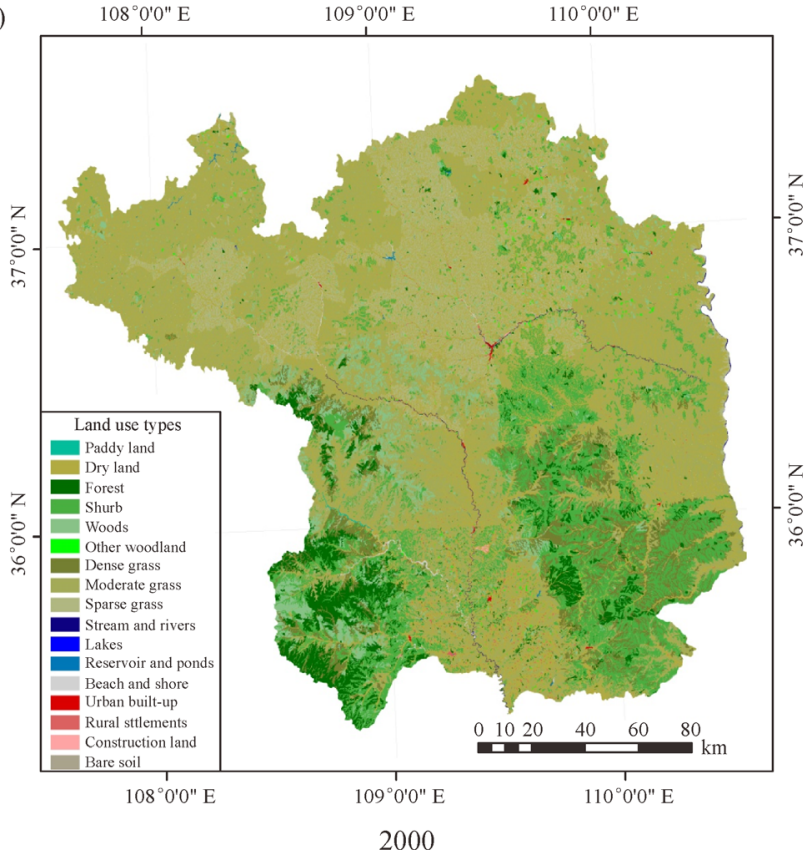

(b)

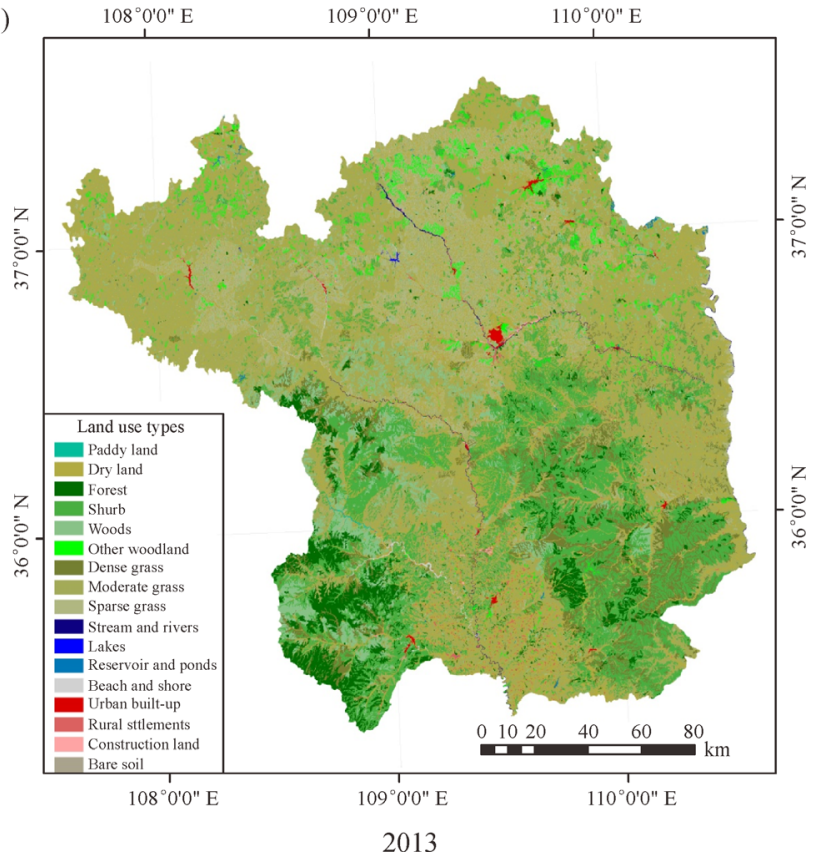

Fig. 1 Land use in Yan'an, Shaanxi Province, China in 2000 (a) and 2013 (b) 
the extension of cities and towns which are mainly situated in valleys becomes a problem. Thus, the Gully Land Consolidation (GLC) Project was launched, aiming to reach a balance between the GFG Project, grain production and urbanization in the Loess Plateau ${ }^{[14]}$.

In general, the GLC Project consists of two parts. First, small scale watershed management is carried out at the bottom of the low mountains and hilly areas by filling and flattening ditches, constructing silt retention dams, flood channels and building irrigation facilities. This has effectively reduced the potential energy difference of the gullies, and improved the water and nutrient storage capacity of the soils ${ }^{[15]}$. New farmland is created in the valleys, and then allocated to local farmers (Fig. 2). Most importantly, the productivity of the new farmland is three times that of the hilltops, and five times the productivity of slopes $^{[16]}$. In 2013, the Chinese Government approved an area of $33733 \mathrm{hm}^{2}$ for the GLC Project in Yan'an, with a total investment of 4.83 billion CNY from 2013 to 2017. The GLC Project is expected to be extended to other areas of the Plateau in the future.

Second, to cater for urban extension due to the growing urban population, the idea of removing the tops of certain hills to fill in valleys to create construction land was conceived and implemented. Yan'an, which is situated in a valley, has been leading a land-creation project based on substantial technical demonstrations by leading scientists in the fields of exploration, geo-engineering, hydrology, water conservation and ecological environment (Fig. 3). Repeatedly compacting the back-fill areas in layers is used to eliminate the loess collapsibility. Then, the excavation area is not extended to the backfilled area until the natural sedimentation becomes stable ${ }^{[17]}$. Through this project, an estimated $80 \mathrm{~km}^{2}$ of flat land will be created in Yan'an. In the meantime, the land-creation project is helping to resettle those who are currently living in to geological hazard-prone areas on the Plateau.

\subsection{Benefits}

Many benefits have arisen from these huge consolidation projects on the Loess Plateau, shifting from distorted to coordinated relationship between humans and the land (Fig. 4). First, the GFG Project has greatly improved the ecological quality of the Plateau, with an increase in the forestry and grass coverage of $11.5 \%$ from 2000 to 2008 . Meanwhile, the annual input of silt and sediment in the Yellow River dropped from over 1.6 billion tons in the 1970s to 300 million tons ${ }^{[18]}$. This huge achievement greatly reduced water loss and soil erosion of the Loess Plateau, laying a solid foundation for the GLC Project, and ensuring sufficient water and soil fertility of the new farmland.

Second, the GLC Project helped strengthen the achievements of the GFG Project, and protect the quality of the land ecosystems of the Loess Plateau. The need to reclaim slopes, which are ecologically fragile, is largely eliminated through the work of the GLC Project, which creates additional flat and productive farmland in the valleys. As the expansion of urban space is directed to the newly created land on hills, cities can better use their hinterland for urban and industrial development. This will further accelerate rural development through agricultural industrialization and rural tourism on the Plateau.

In addition, the local farmers gain significant benefit from the planting of forest or fruit trees on hilltops and slopes, and from cultivating the new farmland. With more farmers migrating to cities, grain production on the Loess Plateau has shifted from extensive cultivation with low yields to more intensive cultivation with higher yield as a result of increased scale of operation and agricultural mechanization. Statistics for the five prefecture-level cities of the Shaanxi Province show that as a result of the GFG

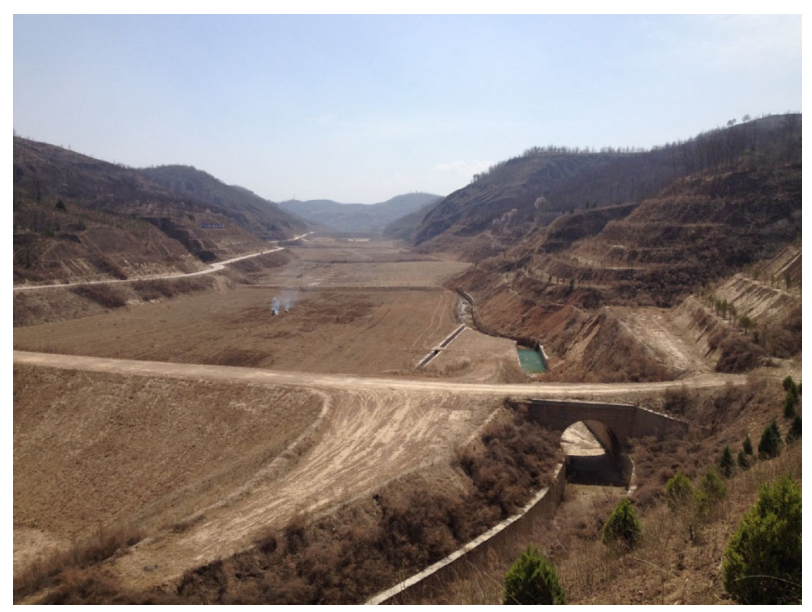

Fig. 2 New farmland created in a valley in Yan'an, Shaanxi Province, China

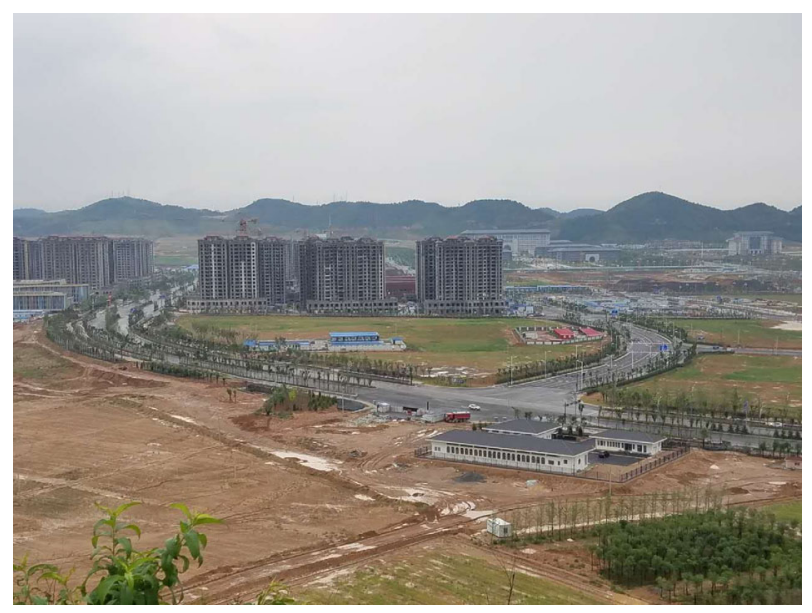

Fig. 3 New construction land created in Yan'an, Shaanxi Province, China 


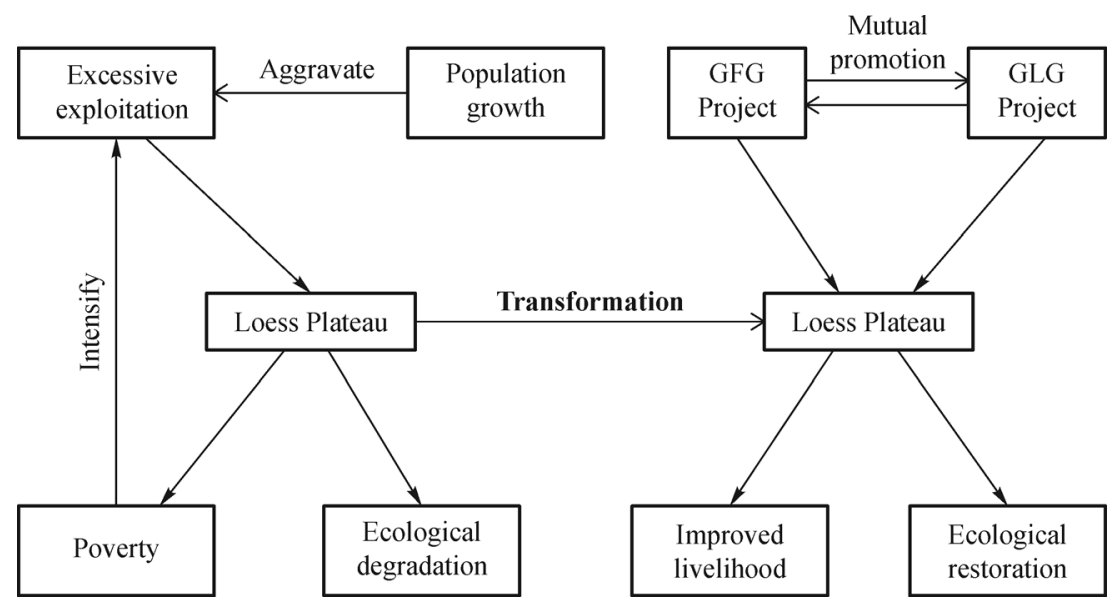

Fig. 4 The transformation of the Loess Plateau, China

Project, the cropped area decreased from 2.28 to 1.87 million $\mathrm{hm}^{2}$ from 1996 to 2012, with a concurrent increase in grain yield from 3.07 to 4.28 tons per hectare ${ }^{[19,20]}$.

\section{Conclusions}

Generally, the Loess Plateau has been shifting from a problem-prone area to an eco-friendly one. The success of the GFG and GLC Projects lies in their complementarities which contribute to coordination of the ecological protection, living standards and production activities on the Loess Plateau. When there is a call for systematic review of land use policy in China ${ }^{[21]}$, the GFG and GLC Projects should be jointly implemented as an ongoing policy, and extended, if feasible, to the mountainous and hilly territories that make up two-thirds of the Plateau. This will contribute to increasing cultivated land and food security in China. In the meantime, the funds for geological hazards protection, poverty alleviation and farm production which are separately operated by different bureaus and departments should be incorporated into a consolidated project for the Loess Plateau.

As considerable numbers of young people from farming families choose to work and live in cities, it becomes necessary to be innovative in agricultural management as more farmland is created on the Loess Plateau. Generally speaking, diversified and larger scale management of agriculture proves more competitive than farming on small household plots in the market economy of modern China ${ }^{[22]}$. Thus, suitable policies should be developed to encourage large agricultural companies or cooperatives to rent land from farmers. Meanwhile, the governments and enterprises are responsible for creating more job opportunities for the rural population.

The successful transformation of the Loess Plateau shows the benefits of a holistic approach incorporating various components of the human and natural systems ${ }^{[23]}$. This achievement is made following the laws of nature and of social development. It has become clear that the relationship between humans and the land on the Loess Plateau can be effectively improved through land consolidation under the guidance of scientific planning and management. Also, China's practice and experience in transforming the Loess Plateau provides a good model for revitalizing, exploring and sustaining less developed and ecological fragile zones around the world.

Acknowledgements This study was supported by the National Social Science Foundation of China (15ZDA021) and National Natural Science Foundation of China (41130748, 41301190, 41471143).

Compliance with ethics guidelines Yuheng Li, Guoming Du, and Yansui Liu declare that they have no conflict of interest or financial conflicts to disclose.

This article does not contain any studies with human or animal subjects performed by any of the authors.

\section{References}

1. National Research Council. Basic Research Opportunities in Earth Science. Washington, D.C.: National Academy Press, 2001

2. Richter D D, Mobley M L. Monitoring earth's critical zone. Science, 2009, 326(5956): 1067-1068

3. Lin H. Earth's critical zone and hydropedology: concepts, characteristics and advances. Hydrology and Earth System Sciences, 2009, 6(2): 3417-3481

4. Laflen J M, Tian J L, Huang C H. Soil erosion and dryland farming. Boca Raton: CRC Press, 2000

5. Shang $X, \operatorname{Li} X$ Q. Holocene vegetation characteristics of the southern Loess Plateau in the Weihe River valley in China. Review of Palaeobotany and Palynology, 2010, 160(1-2): 46-52

6. Fu B. Soil erosion and its control in the loess plateau of China. Soil Use and Management, 1989, 5(2): 76-82

7. Cai Q G. Soil erosion and management on the Loess Plateau. 
Journal of Geographical Sciences, 2001, 11(1): 53-70

8. Qin Y B, Xin Z B, Yu X X, Xiao Y L. Influence of vegetation restoration on top soil organic carbon in a small catchment of the loess hilly region, China. PLoS ONE, 2014, 9(6): e94489

9. Xu Z G, Bennett M, Tao R, Xu J T. China's sloping land conversion programme four years on: Current situation, pending issues. International Forestry Review, 2004, 6(3-4): 317-326

10. Feng X M, Fu B J, Lu N, Wu B F. How ecological restoration alters ecosystem services: an analysis of carbon sequestration in China's Loess Plateau. Scientific Reports, 2013, 3(2846): 1-5

11. Liu J. China plans to implement Grain for Green Project in the Loess Plateau and other two regions. http://www.farmer.com.cn/xwpd/ jsbd/201206/t20120604_721498.htm, 2015-12-24 (in Chinese)

12. Ting Yang- Shaanxi. 17.14 million mu arable land reduction in 14 years. http://news.xinhuanet.com/local/2014-06/24/c_1111294524. htm, 2015-12-24 (in Chinese)

13. Chen Y P, Wang K B, Lin Y S, Shi W Y, Song Y, He X H. Balancing green and grain trade. Nature Geoscience, 2015, 8(10): 739-741

14. Liu J G, Mooney H, Hull V, Davis S J, Gaskell J, Hertel T, Lubchenco J, Seto K C, Gleick P, Kremen C, Li S X. Systems integration for global sustainability. Science, 2015, 347(6225): 1258832

15. Liu Q, Wang Y Q, Zhang J, Chen Y P. Filling gullies to create farmland on the Loess Plateau. Environmental Science \& Technology, 2013, 47(14): 7589-7590

16. Huailong Z, Zhandong H, Zhuo L. Gully Land Consolidation benefits the people, rebuild a good south in North Shaanxi. http:// www.gtzyb.com/yaowen/20121116_23540.shtml, 2015-12-16 (in Chinese)

17. Liu Y S, Li Y H. Environment: China's land creation project stands firm. Nature, 2014, 511(7510): 410

18. Zhou W J, An Z S. Suggestions of implementing Gully Land Consolidation Project which is the same important as the Grain for Green Project. China Science Daily, http://www.cas.cn/xw/zjsd/ 201409/t20140919_4209929.shtml, 2015-12-19 (in Chinese)

19. Shaanxi Provincial Bureau of Statistics. Shaanxi statistical yearbook. Beijing: China Statistics Press, 1997, (in Chinese)

20. Shaanxi Provincial Bureau of Statistics. Shaanxi statistical yearbook. Beijing: China Statistics Press, 2013 (in Chinese)

21. Liu Y S, Fang F, Li Y H. Key issues of land use in China and implications for policy making. Land Use Policy, 2014, 40(1): 6-12

22. Li Y H. Agricultural cooperatives for urban-rural interaction in China. Italian Journal of Agricultural Science, 2013, 12(1): 29-38

23. Liu Y S, Guo Y J, Li Y R, Li Y H. GIS-based effect assessment of soil erosion before and after gully land consolidation: a case study of Wangjiagou project region, Loess Plateau. Chinese Geographical Science, 2015, 25(2): 137-146 